\title{
Influence of Northwest Cloudbands on Southwest Australian Rainfall
}

\author{
Nicola Telcik and Charitha Pattiaratchi \\ School of Civil, Environmental and Mining Engineering, The UWA Oceans Institute, The University of Western Australia, \\ 35 Stirling Highway, Crawley, WA 6009, Australia \\ Correspondence should be addressed to Charitha Pattiaratchi; chari.pattiaratchi@uwa.edu.au
}

Received 31 December 2013; Accepted 5 March 2014; Published 8 April 2014

Academic Editor: Silvio Gualdi

Copyright (C) 2014 N. Telcik and C. Pattiaratchi. This is an open access article distributed under the Creative Commons Attribution License, which permits unrestricted use, distribution, and reproduction in any medium, provided the original work is properly cited.

\begin{abstract}
Northwest cloudbands are tropical-extratropical feature that crosses the Australian continent originating from Australia's northwest coast and develops in a NW-SE orientation. In paper, atmospheric and oceanic reanalysis data (NCEP) and Reynolds reconstructed sea surface temperature data were used to examine northwest cloudband activity across the Australian mainland. An index that reflected the monthly, seasonal, and interannual activity of northwest cloudbands between 1950 and 1999 was then created. Outgoing longwave radiation, total cloud cover, and latent heat flux data were used to determine the number of days when a mature northwest cloudband covered part of the Australian continent between April and October. Regional indices were created for site-specific investigations, especially of cloudband-related rainfall. High and low cloudband activity can affect the distribution of cloudbands and their related rainfall. In low cloudband activity seasons, cloudbands were mostly limited to the south and west Australian coasts. In high cloudband activity seasons, cloudbands penetrated farther inland, which increased the inland rainfall. A case study of the southwest Australian region demonstrated that, in a below average rainfall year, cloudband-related rainfall was limited to the coast. In an above average rainfall year, cloudband-related rainfall occurred further inland.
\end{abstract}

\section{Introduction}

The northwest cloudband (NWCB) is one of three tropicalextratropical cloudbands that crosses the Australian continent [1]. It originates from Australia's northwest coast (Figure 1(a)) and develops a NW-SE orientation, with no immediate connection to southern frontal systems [2]. Extratropical cloudbands are not unique to Australia; they also occur over Southern Africa [3], over South America, and in the Northern Hemisphere [4]. The Northern Hemisphere equivalent, the southwest (SW) cloudband, extends from Central America to the North American east coast and from Indochina to Japan and is most pronounced in winter [1]. Kuhnel [4] defined 14 tropical-extratropical cloudbands around the globe (seven in each hemisphere). The NWCB is the third most frequently occurring cloudband globally and the fourth most frequently occurring cloudband in the Southern Hemisphere.

The NWCB is a large cloud structure, which can reach a length of $8000 \mathrm{~km}$ from northwest (NW) to southeast (SE)
[5]. It can connect a cold front at its $\mathrm{SE}$ end to the intertropical convergence zone at its NW end [6]. If the SE end reaches the Pacific Ocean, the NWCB can also connect to the South Pacific convergence zone [6].

Cloudbands are prominent in Australia during autumn and early winter when the ocean waters around Australia are warm and the subtropical jet stream is strong [1]. The decline in cloudbands in late winter and early spring has been attributed to the cooling of the surrounding oceans [5]. An interannual signal is also present with cloudbands, which may be related to the oceanic conditions in the cloudband formation region [5]. NWCBs are formed through the broad-scale ascent of moist, poleward, and tropical air by a midlatitude baroclinic and could transport latent heat and moisture into higher latitudes [1].

It has been estimated [1] that cloudband-related rainfall provides up to $80 \%$ of the annual rainfall for NW Australia and up to $40 \%$ of the annual rainfall for SW Australia. Recent positive trends in winter rainfall over northwest Western Australia and Central Australia have been attributed to increased 


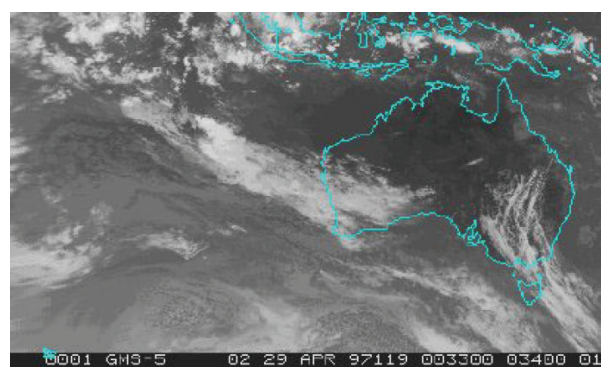

(a)

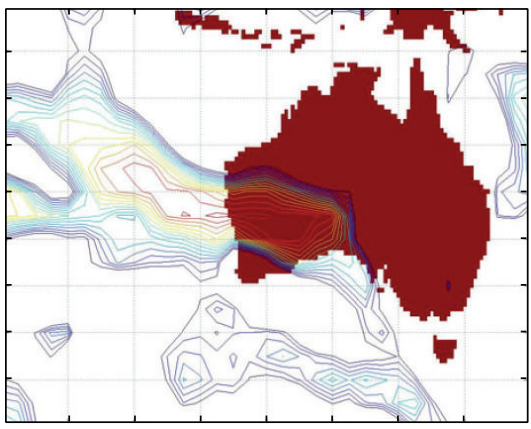

(c)

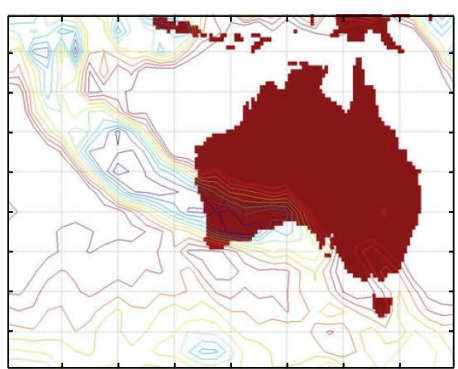

(b)

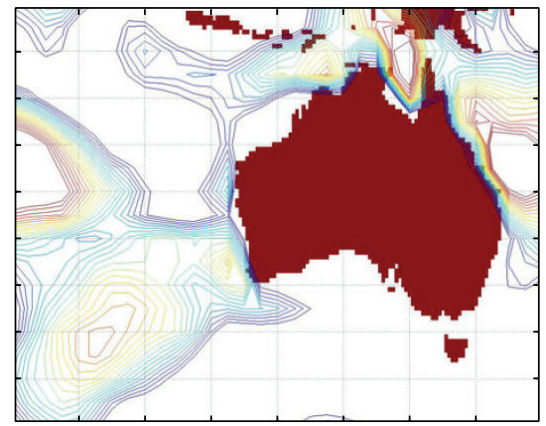

(d)

Figure 1: (a) Satellite image of a NWCB on 29 April 1996 (image source: Australian Bureau of Meteorology) and corresponding (b) OLR contours (140-250 W/m²), (c) TCC contours (70-100\%), and (d) latent heat flux contours $\left(110-300 \mathrm{~W} / \mathrm{m}^{2}\right)$.

northwest cloudband activity [7]. Southern Australia receives most of its cloudband-related rainfall through convective activity, such as cloudbands interacting with cold fronts [1]. Frontal systems produce most of the rainfall that occurs over SW Australia; however, the interaction of these systems with NWCBs increases the rainfall resulting from the frontal system [1]. Thus knowledge of NWCBs and their interactions with other weather phenomena is important for seasonal rainfall forecasting in Australia.

Wright [1] defined "interaction" as the "capture of lowlatitude moisture (north of $23^{\circ} \mathrm{S}$ ), as represented by cloud masses in the circulation of a mid and low-latitude front or depression, and the subsequent amalgamation of mid and low-latitude cloud systems." An interaction is not defined until amalgamation of the mid- and low-latitude cloud systems has occurred or if there is evidence of cyclonic curvature at the SW end of the cloudband, where there are suspected cloudband-associated interactions [1].

1.1. Climate Influences on Northwest Cloudbands. The Indian Ocean is not an isolated water body. Teleconnections with other oceans through atmospheric and oceanic circulations affect the Indian Ocean (e.g., $[8,9])$. Meehl [10] studied the precipitation, sea level pressure, and sea surface temperature (SST) in the Indo-Pacific to reveal a dynamically coupled ocean-atmosphere system. Variations in this system can affect NWCB formation; however, Webster et al. [11] found no connection between SST and the outgoing longwave radiation (OLR) to the NW of the NWCB formation region in the Indian Ocean. Webster et al's findings suggest that atmospheric dynamical processes or instabilities, not oceanatmosphere interactions with warm SSTs, mainly produce the convection that occurs in this region.

Two direct influences on NWCB activity are the MaddenJulian oscillation (MJO) and the Indian Ocean dipole. Both phenomena have been observed in the NWCB formation region in the Eastern Indian Ocean. The El Niño southern oscillation also affects NWCBs through tropical forcing.

The MJO, or intraseasonal oscillation, occurs during fluctuations in tropical rainfall on the scale of 30-60 days $[12,13]$. These fluctuations are visible in the wind, SST, precipitation, and cloudiness fields $[3,14]$. The MJO moves east across the tropics towards the Australian continent every 30-50 days and can set up the synoptic conditions (winds, pressure, convection, and cloudiness) conducive to NWCB development. The MJO also has an influence on cloudbands across Southern Africa [3].

The Indian Ocean dipole (IOD), which occurs every four to five years, is an oscillation of opposing, anomalous SSTs off Sumatra and in the Western Indian Ocean, with accompanying wind and precipitation anomalies [15]. Strong coupling between the air-sea processes is unique to the Indian Ocean; however, this coupling is not completely independent of the El Niño southern oscillation[16]. Ummenhofer et al. [8] found that major droughts in southeast Australia were related to periods when the IOD remained persistently "positive" or "neutral" whilst during a negative phase of the IOD, unusually wet conditions dominated across southern regions of Australia. The dipole mode index [15] is based on monthly SST anomalies between the Western Indian Ocean $\left(50-70^{\circ} \mathrm{E}\right.$, $\left.10-10^{\circ} \mathrm{N}\right)$ and the Eastern Indian Ocean $\left(90-110^{\circ} \mathrm{E}, 10-0^{\circ} \mathrm{S}\right)$. 


\section{Methodology}

2.1. Data. Several data sets were used in this study of NWCBs and their effects on Australian rainfall:

(1) satellite images for 1997 and 1999 from the Australian Bureau of Meteorology,

(2) National Centers for Environmental Prediction (NCEP) reanalysis data for 1950-1999 from the Climate Diagnostics Center, Colorado, including:

(i) daily total cloud cover (TCC) and latent heat flux on a $2 \times 2^{\circ}$ grid,

(ii) six-hour mean sea level pressure; wind fields at $250,300,400,500,600$, and $700 \mathrm{hPa}$; geopotential heights at 500 and $700 \mathrm{hPa}$ on a $2.5 \times 2.5^{\circ}$ grid,

(3) daily interpolated OLR on a $2.5 \times 2.5^{\circ}$ grid for $1974-$ 1998 from the Climate Diagnostics Center, Colorado,

(4) Australian daily rainfall data for 1950-1999 from the Australian Bureau of Meteorology,

(5) one-degree Australian daily rainfall data for 19501999 from the Australian Bureau of Meteorology Research Centre (Drosdowsky, pers. comm.); the gridded rainfall was based on the interpolation of the data obtained with the rainfall gauges,

(6) Reynolds reconstructed mean monthly SST for 19501999 from the Climate Diagnostics Center, Colorado.

2.2. Northwest Cloudband Activity. Satellite data from April to October in 1997 and 1999 were used to analyse NWCBs over Australia. All the days between April and October that had some portion of a NWCB were collated. Cloudband activity days were isolated to determine the atmospheric conditions conducive to cloudband formation (see also [3]). Fifty-three days of cloudband activity were recorded and used for the composite of NWCB activity.

The wind fields, mean sea level pressure, and geopotential heights at $500 \mathrm{hPa}$ over the Eastern Indian Ocean were used to identify the NWCBs; however, it was hard to identify NWCBs using these parameters because NWCBs have similar baroclinic features to a strong frontal system that crosses SW Australia, although the NWCBs did not appear to be connected to this southern frontal system [2]. This preexisting baroclinicity, which the NWCB moves through, is reinforced by the passage of a second cold front through SE Australia [2]. Bell [17] found that this baroclinic instability over Australia caused NWCBs. The OLR distributions were more useful for identifying NWCBs because NWCBs were visible in the OLR fields and distinguishable from other cloud features within the range of $140-250 \mathrm{~W} / \mathrm{m}^{2}$.

When the OLR distributions satisfied the prescribed NWCB criteria and some portion was located over the Australian continent the corresponding date was recorded as a "cloudband day" and the NWCB was defined as "mature." The NWCB index is a representation of cloudband days influencing the study region. Surges in tropical energy can reinforce
NWCBs before the NWCBs dissipate [4], which makes it hard to discern whether a cloudband has dissipated and a new one has formed or whether the original cloudband persists. A cloudband's lifetime can vary considerably; thus it was more useful to include the number of days in which a NWCB was over part of Australia than how many cloudbands crossed over the continent.

The criteria for a cloudband day were defined from the studies of Tapp and Barrell [5], Kuhnel [18], and Wright [1] and included the dimensions, orientation, composition, and the formation region as follows:

(1) a cloudband in a NW-SE orientation with a length greater than $2000 \mathrm{~km}$ and a width of at least $450 \mathrm{~km}$; this orientation could range from NNW-SSE to WNW-ESE;

(2) a generating or initiation region over the Eastern Indian Ocean (or Northern Australian waters east to $\left.130^{\circ} \mathrm{E}\right)$;

(3) a continuous cloud structure, the grid field was $2.5 \times$ $2.5^{\circ}$, but the NWCB structure was much larger than the OLR or TCC grid fields and could be located as a continuity in these fields;

(4) a section of the cloudband was located over the Australian continent.

Contour lines of equal OLR or TCC were used to detect NWCBs. These contour lines also had to meet the above criteria before the day was recorded as a cloudband day. The confirmed cloudband days were used to produce a NWCB index for 1974-1999, which was verified with satellite images from 1997 and 1999. To extend the index to 1950, the TCC was used as a proxy for the OLR.

A satellite image of a NWCB on 29 April 1996 and the corresponding OLR contours are shown in Figures 1(a) and $1(\mathrm{~b})$, respectively. The TCC is presented as a percentage between 0 and 100 and treats the atmosphere as one layer; thus NWCBs can be difficult to locate because the cloudband's coherent structure can be obscured. More cloud activity was revealed over the Southern Indian Ocean with the TCC data than with the OLR data, which made it hard to distinguish a clear cloudband perimeter; however, when the latent heat flux data for the Southern Indian Ocean were used, most of this cloud "noise" was screened. The screen was based on a latent heat flux of $>100 \mathrm{~W} / \mathrm{m}^{2}$ in the region of $80-105^{\circ} \mathrm{E}, 22.5-35^{\circ} \mathrm{S}$; thus the TCC data for these grid points were removed.

Kuhnel [4] defined the cloudband formation region as $90-145^{\circ} \mathrm{E}$; however, the analysis of satellite and OLR data showed that this region did not capture all the mature NWCBs present over Australia. The east end of this region $\left(145^{\circ} \mathrm{E}\right)$ captured cloudbands that did not have the characteristic NW-SE orientation of a NWCB. These cloudbands were most likely the continental cloudbands that Wright [1] described. Therefore this study focused on NWCBs in the region of $80-130^{\circ} \mathrm{E}$.

2.3. Northwest Cloudband Activity and Rainfall. Transects of the cloudband starting at $110^{\circ} \mathrm{E}$ and moving east were 
extracted to identify the NWCBs over Australia. The centre of a NWCB was defined as the local minimum in the OLR field and the local maximum in the TCC field and defining the OLR and TCC to the north and south of this point. When the values were within the OLR range (i.e., $140-250 \mathrm{~W} / \mathrm{m}^{2}$ ) and TCC range (60-100\%) for a NWCB and generally decreased (OLR) or increased (TCC) from the local minimum, frontal disturbances that were not interacting with the cloudband showed a decrease in OLR and an increase in TCC. The OLR field (with NWCB coverage shaded) for 10 June 1998 is shown in Figure 2(a), and the corresponding land mask of cloudband activity is shown in Figure 2(b). In Figure 2(b), "1" denotes that a NWCB was recorded in the $2.5^{\circ}$ grid, and " 0 " denotes that no NWCB was recorded in that grid.

Two data sets were obtained from the Australian Bureau of Meteorology to analyse the cloudband-related rainfall. The first data set was a daily gridded $\left(1^{\circ}\right)$ rainfall data set (Drosdowsky, pers. comm.), which was used for the largescale analysis of the cloudband-related rainfall. The second data set consisted of daily rainfall station data. If part of a NWCB was detected in a particular grid, the rainfall that occurred in the corresponding grids was recorded as cloudband-related rainfall. The rainfall gauge data and cloudband-related rainfall data were collated for each month and each NWCB season (April-October) to study the spatial and temporal trends of the NWCBs. If NWCBs were detected in the $2.5^{\circ}$ grid containing the gauge, any rainfall recorded that day was classified as cloudband-related. Cloudbandrelated rainfall data for the NWCB season were collated for each year and compared with the total April-October rainfall data for that gauge.

\section{Results and Discussion}

3.1. Northwest Cloudband Climatology. The synoptic conditions associated with a NWCB across Australia generally showed a high-pressure cell over Central and Southern Australia and another pressure cell over the Southern Indian Ocean at around $80^{\circ} \mathrm{E}$. Downey et al. [2] also observed these high-pressure features. Between the two pressure cells, a deepening trough was located over the west Australian coast, which connected with a midlatitude depression off the SW coast (see Figure 3(a), which is based on a composite of 327 events of NWCBs between 1979 and 1999). Highpressure systems over the Indian Ocean and Central/SE Australia framed this tropical-extratropical connection of low pressures. A concentration of surface latent heat fluxes was also observed in the NWCB formation region $\left(80-100^{\circ} \mathrm{E}\right.$, $10-20^{\circ} \mathrm{S}$ ) (Figure 3(b)).

NWCBs are also associated with an upper-level trough in the Southern Indian Ocean at $80-100^{\circ} \mathrm{E}$. This trough is not apparent in the composite of geopotential heights at $500 \mathrm{hPa}$ in Figure 3(c) because of the longwave trough's differing amplitudes. The upper-level wind fields at $500 \mathrm{hPa}$ showed a NW airstream over Australia from the NWCB formation region (Figure 3(d)), which was related to the upper-level trough. The upper-level winds formed a NW-SE "jet" near the NWCB formation region, along which the cloudband followed.

NWCB development is associated with the leading edge of a midlatitude upper-level trough. Downey et al. [2], Bell [17], and Tapp and Barrell [5] found that this upper-level trough, or cut-off low, was generally located off SW Australia. Wright [19] found that the trough's amplitude was correlated with the southern oscillation index (an indicator of the El Niño southern oscillation), an average winter Eastern Indian Ocean cloudiness, and average NW Victorian rainfall. The amplitude and position of this upper-level trough can vary; hence it is not well defined in Figure 3(d). Kuhnel [18] stated that not all upper-level troughs were well defined and that two out of ten upper-level troughs might have small amplitudes. We found that four out of ten upper-level troughs had a NWSE orientation, which is characteristic of NWCBs.

3.2. A Northwest Cloudband Index. The OLR, TCC, and latent heat flux data were used to create a NWCB index for 19501999. The seasonal variability of the NWCB index is shown in Figure 4 . The five-year, centred, weighted, running mean is included in the figure. Between April and October of 19501999, a mature cloudband was recorded over Australia on about 30 days. These NWCBs lasted from a day to more than a week (see Figure 5).

Several extreme NWCB events shown in Figure 4 were related to the El Niño southern oscillation. For example, NWCB activity was low in 1982 and 1986, which corresponded to El Niño years (1982-1983 and 1986-1987); however, NWCB activity was high in 1998, which corresponded to La Niña years (1998-1999). Indonesian throughflow-induced SST anomalies [20] in the NWCB formation region may have contributed to this relationship between the El Niño southern oscillation and NWCB activity.

Kuhnel [18] showed that Western Australia experienced about 15 cloudband days a year and Central and South Australia experienced about nine cloudbands a year, which showed that cloudband activity over Australia decreased from west to east. The mean seasonal NWCB frequencies over Australia for 1979-1999 are shown in Figure 6. The figure shows that the NWCB activity had a NW-SE bias. The state average in this study was slightly higher than that in Kuhnel's [18] study. The high cloudband activities in 1992, 1993, and 1998 caused this increase in the average.

Hirst and Godfrey [21] showed that the SSTs in the Eastern Indian Ocean were linked to the Pacific Ocean via subsurface baroclinic waves. They found regions of convective mixing or strong upwelling that were susceptible to small changes in the throughflow. Variations in the throughflow affect the pattern and response time of the subsurface (and therefore surface) temperature. During El Niño, cool SSTs feed through the Indonesian throughflow into the Eastern Indian Ocean [22], whereas, during La Niña, warm SSTs feed into the Eastern Indian Ocean [22]. These SST anomalies were observed in the NWCB formation region.

The warmer SSTs during La Niña may increase cloudband activity through enhanced convection; conversely, the cooler SSTs during El Niño may decrease cloudband 


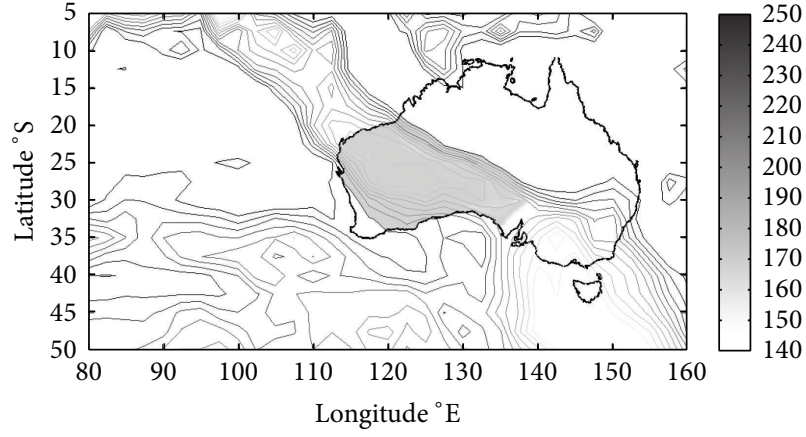

(a)

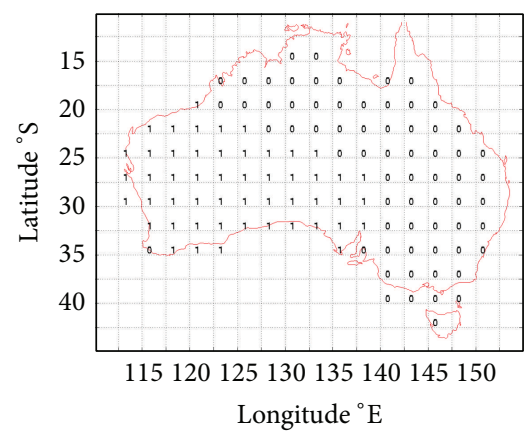

(b)

Figure 2: (a) The OLR field (with NWCB coverage shaded) for 10 June 1998 (OLR in W/m²). (b) The land mask of NWCB activity across Australia used to create the regional NWCB indices. "1" denotes NWCB coverage for that grid.

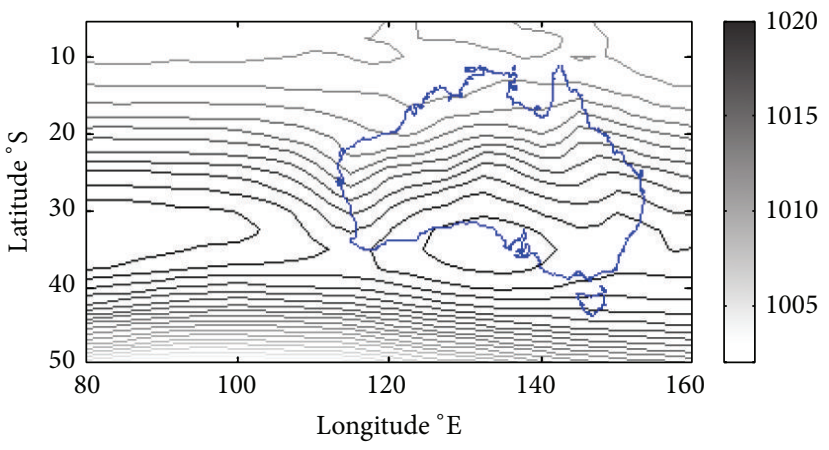

(a)

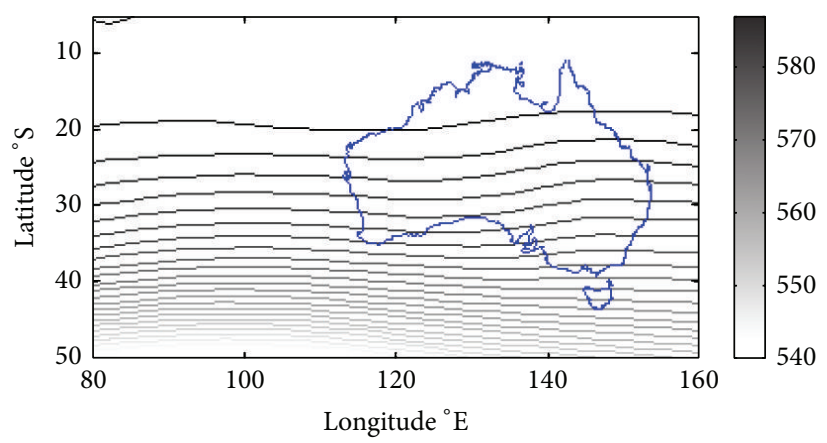

(c)

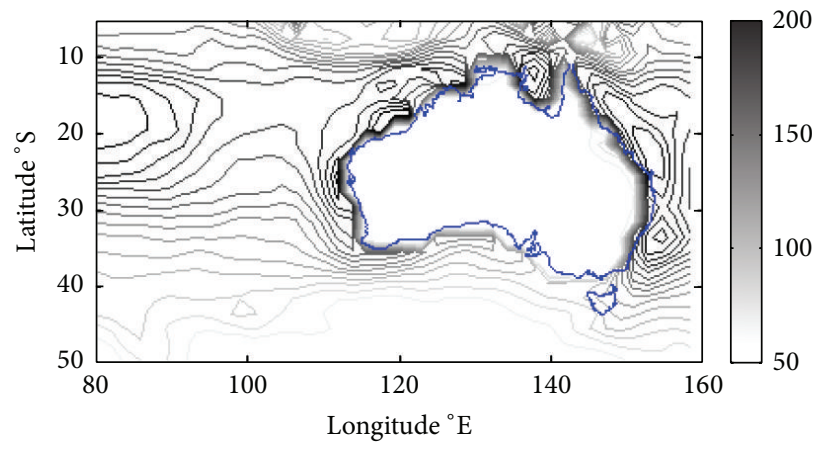

(b)

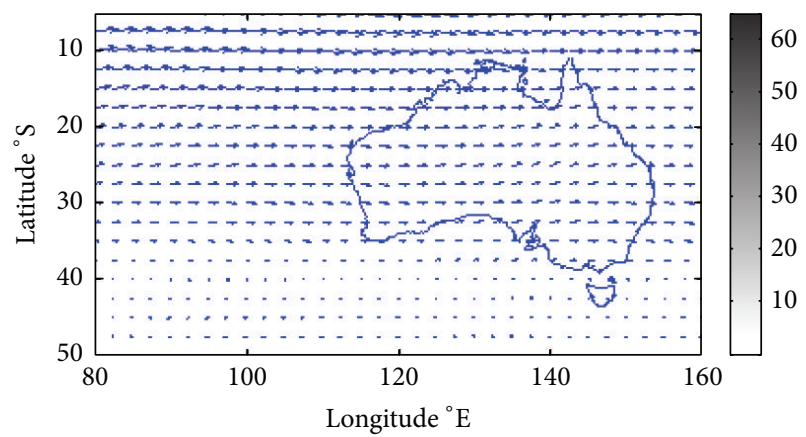

(d)

Figure 3: Composites of 327 NWCB events between 1979 and 1998 showing conditions associated with NWCB activity: (a) mean sea level pressure in $\mathrm{hPa}$; (b) latent heat fluxes in $\mathrm{W} / \mathrm{m}^{2}$; (c) geopotential height at $500 \mathrm{hPa}$ in $\mathrm{dm}$; (d) upper-level wind fields at $500 \mathrm{hPa}$.

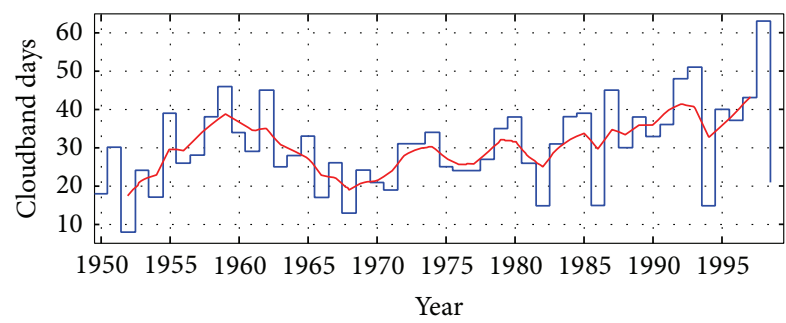

FIgUre 4: The NWCB index for Australia. The index represents the number of days in a season (April-October) in which a NWCB was located over part of Australia. A five-year, weighted, running mean was fitted to this index. activity through reduced convection. Wright [1] showed that enhanced cloudband activity was associated with warm SST anomalies in the NWCB formation region and cool SST anomalies directly to the SW of this region. This reflects similar regions in an Indian Ocean dipole defined by Nicholls et al. [25].

3.3. Factors Influencing Northwest Cloudband Activity. Meehl [23] showed that SST anomalies on the scale of a season, associated with wind anomalies, affected air-sea interactions (especially evaporation) and therefore the latent heat release. Strong winds and warm SSTs increase convection 


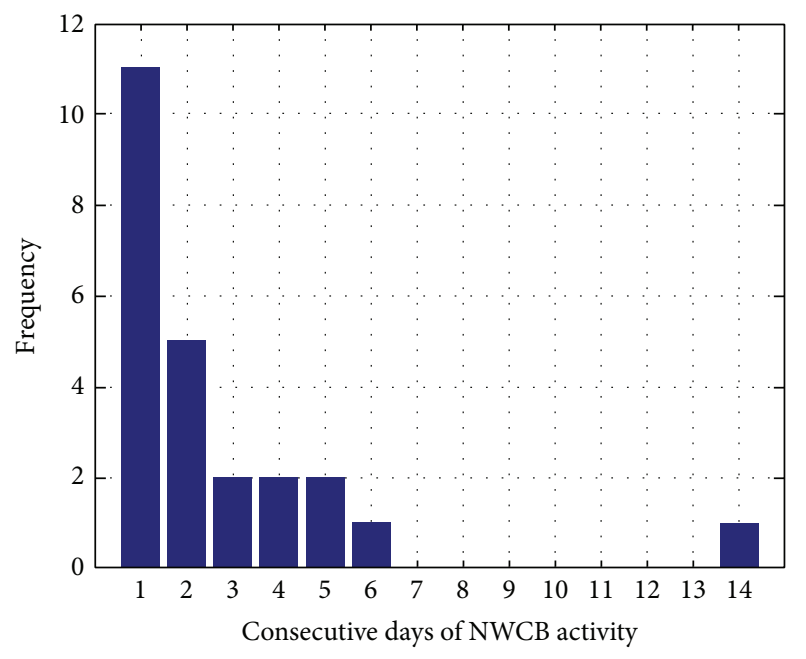

FIGURE 5: The frequency of individual NWCBs over Australia in 1998.

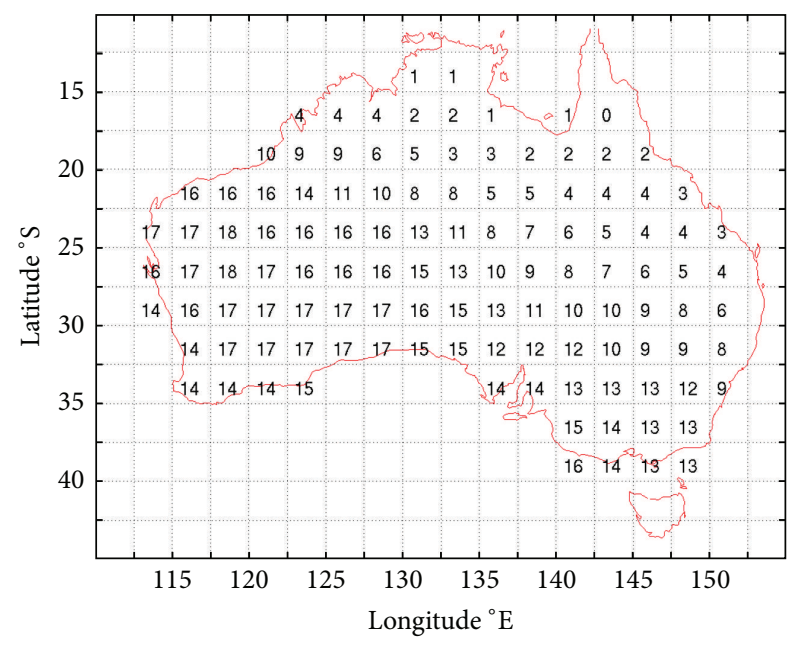

FIGURE 6: The mean seasonal (April-October) NWCB frequencies for 1979-1999.

and evaporation and decrease the sea level pressure. These actions, which are characteristic of monsoons, encourage NWCB formation. Weak winds then decrease evaporation and increase the sea level pressure the following year. This quasi-biennial feature was sometimes observed in the NWCB index (1985 to 1990 in Figure 4). Meehl [24] noted that a tropospheric biennial mechanism involving air-sea interactions was connected with the South Asian or Indian monsoon. This biennial mechanism is quasi-biennial, occurring intermittently or over several years (also apparent in Figure 4 as a noncontinuous biennial feature).

The SST anomalies in the NWCB formation region of 90$100^{\circ} \mathrm{E}, 10-15^{\circ} \mathrm{S}$, in the Eastern Indian Ocean, are referred to as GEN. The correlation between NWCB activity and GEN was 0.61 in April-one of the highest NWCB activity months. The atmospheric dynamical processes might have caused this correlation, as the SST and OLR in a region next to the NWCB formation region were uncorrelated [11].
TABLE 1: Mean monthly (April-October) NWCB days over Australia for 1950-99.

\begin{tabular}{ccccccccc}
\hline & Mar. & Apr. & May & June & July & Aug. & Sep. & Oct. \\
\hline NWCB days & 5.5 & 7.9 & 7.9 & 5.9 & 3.7 & 2.3 & 1.0 & 1.8 \\
\hline
\end{tabular}

TABLE 2: The maximum monthly cross-correlations between NWCB activity and the southern oscillation index (SOI), GEN, the dipole mode index (DMI), the Madden-Julian oscillation (MJO), and Ninol2.

\begin{tabular}{lcc}
\hline Index with NWCB & Correlation $(r)$ & Correlation month \\
\hline SOI & -0.52 & Apr. \\
GEN & 0.61 & Apr. \\
DMI & -0.60 & July \\
MJO & -0.48 & July \\
Nino12 & 0.66 & Apr. \\
\hline
\end{tabular}

Kuhnel [4] found a correlation of -0.36 between NWCB activity and the southern oscillation index (SOI); however, this correlation was based on a slightly different study region and a single year of cloudband activity. The AprilOctober NWCB activity accounted for about two-thirds of the cloudband activity that Kuhnel [4] described. The correlation between NWCB activity and the southern oscillation index in April was -0.52 (Table 2). This inverse relationship suggested that a positive southern oscillation index in April was linked to less NWCB activity and a negative southern oscillation index was linked to more NWCB activity. The SST anomalies in the eastern equatorial Pacific Ocean (Nino12: $\left.80-100^{\circ} \mathrm{W}, 5^{\circ} \mathrm{S}-5^{\circ} \mathrm{N}\right)$ in April were also related to NWCB activity (correlation of 0.66 ). These results showed that the El Niño southern oscillation in April was linked to cloudband activity in the eastern Indian Ocean.

Kuhnel [4] defined cloudband activity as a function of the southern oscillation index, which determines the strength and position of the main convective regions. Fluctuations in convective regions affect NWCB formation. The NWCB formation region is located where the $40-50$ day oscillation (i.e., the MJO) has been observed.

Tapp and Barrell [5] and Kuhnel [4] stated that the NWCB season was between April and October. The results showed more cloudbands were usually present in the first half of the season (April-July). The mean monthly NWCB days for 1950-1999 are shown in Table 1. Cloudband activity generally peaked in May and then decreased over the following months. These results agreed with those of Kuhnel [4] and Wright [1]. Cloudband activity occurred in March but was more irregular and not usually associated with rainfall. Cloudbands present in the warmer months (November-March) are associated with monsoonal depressions or tropical cyclones NW of Australia [4] and are not considered NWCBs.

The duration of a NWCB over Australia varies but can sometimes be up to two weeks (e.g., the NWCB that occurred in 1998, which appeared on 30 March and lasted until 12 April; see Figure 4). If the synoptic conditions are baroclinic, NWCBs can appear consecutively for more than a week. If the baroclinicity is reduced, a cloudband may still form but 


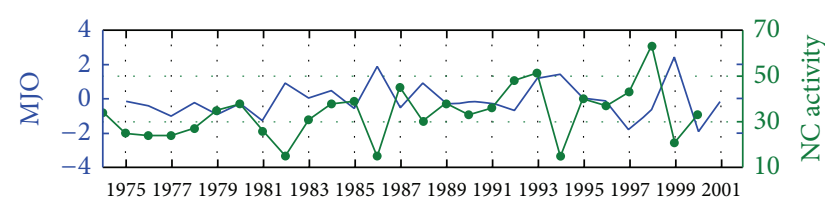

Year

(a)

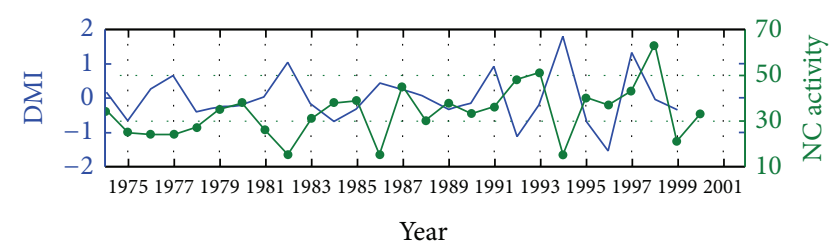

(b)

Figure 7: (a) The mean MJO anomaly and seasonal (April-October) NWCB frequency for 1975-1999 (MJO in W/m², based on OLR values) and (b) the mean dipole mode index anomaly and seasonal (April-October) NWCB frequency for 1975-1999. The dipole mode index represents the temperature anomaly difference $\left({ }^{\circ} \mathrm{C}\right)$.

will usually dissipate after 24 hours. The frequency of NWCB days over Australia between April and October 1998 is shown in Figure 4. The synoptic conditions in April, which favoured cloudband activity, resulted in fourteen days of cloudband activity, followed by more cloudband activity less than a week later. Towards the end of the NWCB season, conditions were unfavourable for cloudband activity and cloudbands tended to dissipate after a day.

An inverse relationship between NWCB activity and the MJO is shown in Figure 7(a). The MJO index was created using OLR anomalies in the region of $90-100^{\circ} \mathrm{E}, 5^{\circ} \mathrm{S}-5^{\circ} \mathrm{N}$. The MJO mainly occurs to the NW of the NWCB formation region, but also crosses into the NWCB formation region [14]. An increase in MJO activity was linked to a decrease in NWCB activity over Australia and more cloudiness (hence lower OLR) in the eastern Indian Ocean. The relationship between NWCB activity and the MJO was strongest in July (correlation of -0.48 ; see Table 2 ).

The NWCB formation region overlaps with the eastern part of the Indian Ocean dipole region. An inverse relationship was found between NWCB activity and the Indian Ocean dipole. The dipole mode index measures the difference in SST between the West and East Indian Ocean and is used to measure the Indian Ocean dipole. The Indian Ocean dipole event of 1994 coincided with one of the lowest recorded NWCB activity seasons. Low NWCB activity also coincided with a peak in warm SSTs in the Western Indian Ocean and cool SSTs in the Eastern Indian Ocean in 1982; this year also corresponded with the 1982-1983 El Niño event. The relationship between NWCB activity and the Indian Ocean dipole was strongest in July (correlation of -0.60 ; see Table 2).

\subsection{Australian Rainfall and Northwest Cloudbands. NWCBs} produce high rainfall amounts in Australia between April and October. In some inland regions where the annual rainfall is low (e.g., $<200 \mathrm{~mm} /$ year), the contribution of $>50 \mathrm{~mm}$ of rainfall from a cloudband can be significant. The interactions of NWCBs with other features, such as troughs, fronts, and convective activity, can also generate rainfall.

Two years of extreme cloudband activity, 1982 and 1998, were chosen for analysis. Cloudband activity was low in 1982, with only 15 NWCB days recorded. The cloudbands were mostly limited to the west and south coasts, with few NWCBS recorded in Central Australia (Figure 8(a)).
Cloudband-related rainfall was also mostly limited to coastal areas, especially the west coast (Figure 8(b)). Most of the inland regions received less than $30 \mathrm{~mm}$ of cloudband-related rainfall between April and October.

Cloudband activity was high in 1998, with 63 NWCB days recorded. The cloudband coverage was more widespread in 1998 (Figure 9(a)) than it was in 1982. The cloudband contribution to inland rainfall, especially over Western Australia, is shown in Figure 9(b). Some of the inland rainfall stations received $65 \%$ of their April-October rainfall from cloudbandrelated activity (see next section). Most of the rainfall stations in Western Australia received $>100 \mathrm{~mm}$ of cloudband-related rainfall between April and October, which is a significant amount for the inland stations.

3.5. Case Study: Southwest Australian Rainfall. Winter rainfall in SW Australia has declined more than 25\% since the 1950s [25]. The decline has affected farming and other industries in coastal and inland regions. Complex interactions between atmospheric and oceanic circulations affect rainfall in the SW, with cold fronts producing most of the winter rainfall. NWCBs and convective activity also generate winter rainfall, but to a lesser degree [26].

Wright [19] and Kuhnel [18] discussed the importance of NWCBs as rainfall generators. Cloudbands can cause heavy rainfall, especially when they interact with an extratropical front (e.g., the cloudband activity in NW Victoria discussed in [19]); however, this heavy rainfall is irregular. A study of the rainfall gauge data associated with cloudband activity revealed this irregularity. The SW rainfall stations were chosen from the high-quality data set that Lavery et al. [27] described. Of these stations, rainfall gauges that were spread evenly over the SW and were $100 \%$ complete for the study period (1950-1999) were selected. The high-quality rainfall stations for the SW Australian region are shown in Figure 10, with the shaded circles denoting the stations chosen for cloudband analysis. These nine rainfall stations, along with their latitudes and longitudes, are listed in Table 3.

When NWCBs cross SW Australia and interact with frontal systems, heavy, widespread rainfall can occur. Cloudbands, and their interactions with cold fronts, account for up to $25 \%$ of the SW winter rainfall [1]. The results from this study showed cloudband-related rainfall was sometimes as high as 65\%, as seen with station 12052 (Menzies) in 1998 (Figure 10). The cloudband-related rainfall, however, 


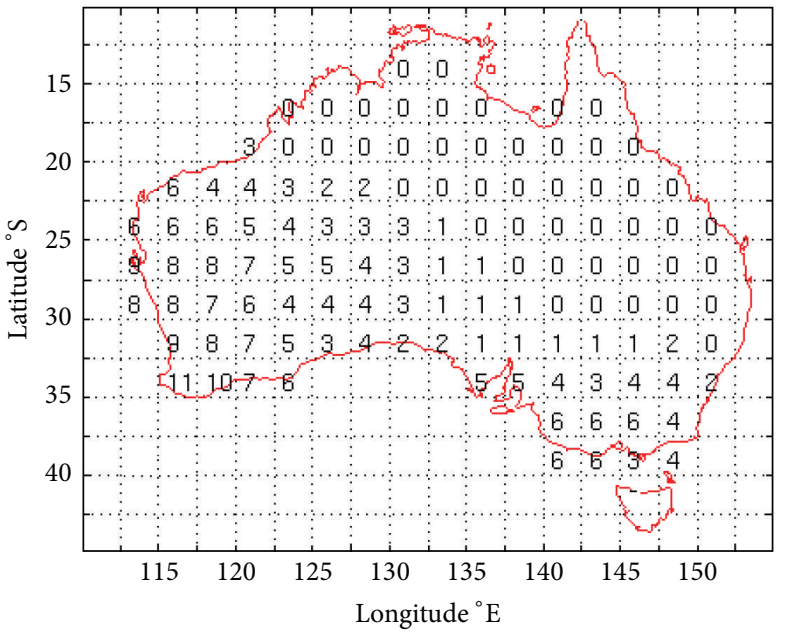

(a)

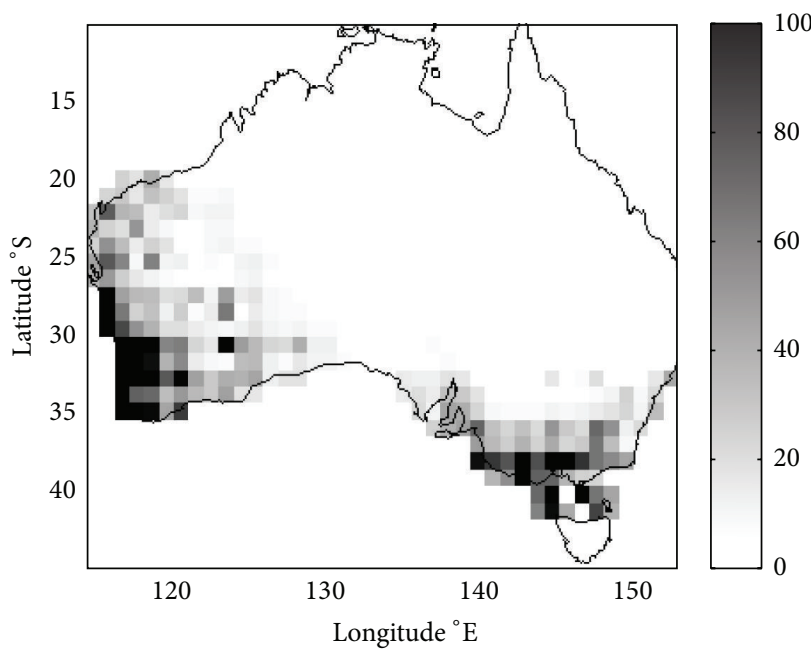

(b)

FIGURE 8: The (a) frequency of NWCB activity and (b) NWCB-related rainfall for 1982 (a low cloudband activity year).

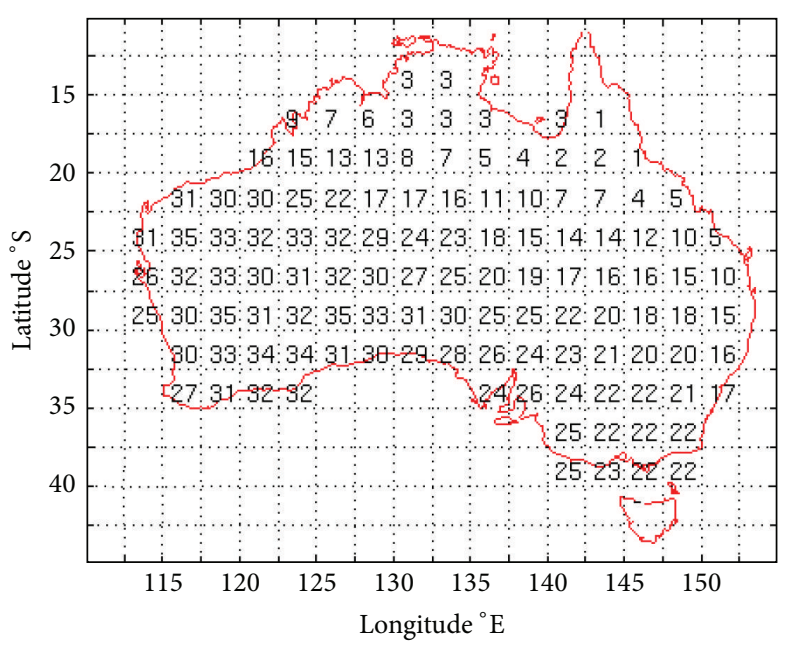

(a)

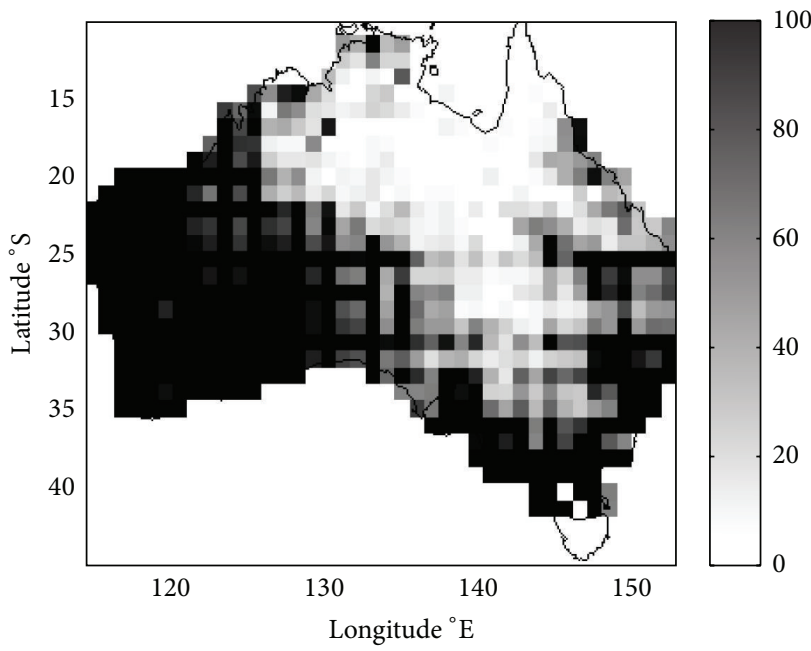

(b)

FIGURE 9: The (a) frequency of NWCB activity and (b) NWCB-related rainfall for 1998 (a high cloudband activity year).

TABLE 3: Details of the SW rainfall stations.

\begin{tabular}{lccc}
\hline Station number & Station name & Latitude $\left({ }^{\circ} \mathrm{S}\right)$ & Longitude $\left({ }^{\circ} \mathrm{E}\right)$ \\
\hline 8147 & Yuna & 28.3261 & 114.9572 \\
9519 & Cape Naturaliste & 33.5381 & 115.0183 \\
9557 & Hopetoun P.O. & 33.9511 & 120.1247 \\
9564 & King River & 34.9444 & 117.9228 \\
9616 & Westbourne & 34.0928 & 116.6603 \\
10092 & Merredin & 31.4769 & 118.2778 \\
10592 & Lake Grace P.O. & 33.1017 & 118.4608 \\
10795 & Avondale Research Station & 32.1189 & 116.8664 \\
12052 & Menzies & 29.6933 & 121.0286 \\
\hline
\end{tabular}




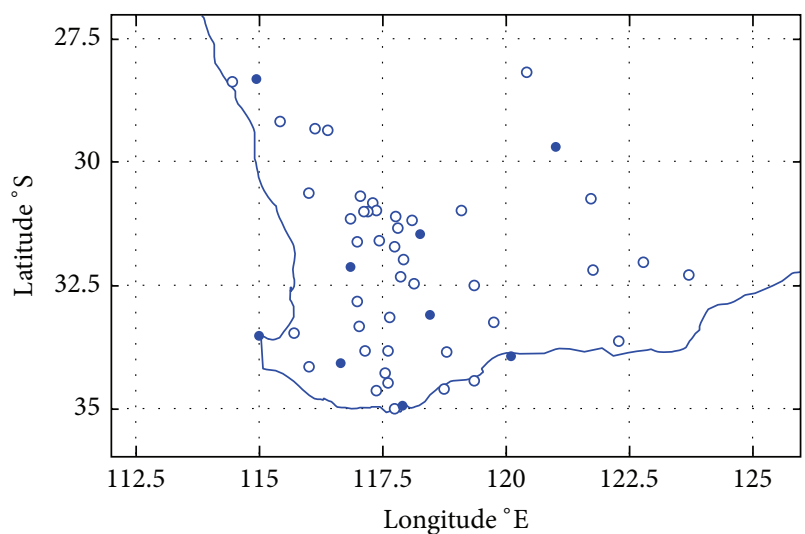

FIGURE 10: The locations of high-quality rainfall stations for the SW Australian region (courtesy of the Australian Bureau of Meteorology). The shaded circles denote the nine rainfall stations used in this study.

was highly variable. For Menzies, for example, the percentage of cloudband-related rainfall was sometimes less than $5 \%$ of the total April-October rainfall.

Over SW Australia, fronts provide a form of uplift for NWCBs. The rainfall produced as a result of cold fronts is much less than that produced from the interaction of cold fronts with NWCBs. Cloudband-related rainfall can exceed $75 \mathrm{~mm}$ a day, whereas frontal activity may produce only $25 \mathrm{~mm}$ of rainfall a day. Kuhnel [18] and Wright [1] showed the rain-producing capacity of a cloudband decreased towards the south and east. In SW Australia, the interaction of cold fronts with NWCBs produced most of the cloudband-related rainfall. In the northern regions (e.g., the Gascoyne-Murchison region), cloudband-related rainfall may occur without these interactions.

The seasonal (April-October) NWCB-related rainfall data for 1975-1999 for the nine stations listed in Table 3 are shown in Figure 11. The coastal stations generally recorded higher rainfall than the inland stations. There was no corresponding upward trend in the rainfall compared with the upward trend in cloudband activity. Between 1975 and 1999, unusually heavy rainfall was recorded in 1980, 1988, and 1998, with 1988 and 1998 corresponding to La Niña years.

The NWCB-related rainfall contributions to the total April-October rainfall varied seasonally and spatially (Figure 12). Years that seem to have no cloudband contribution to rainfall (i.e., 0\%) were due to missing seasonal data. Most of the rainfall stations that recorded high rainfall amounts were located near the coast (e.g., station 9557 in 1980). Cloudbands and their interactions with meteorological features contributed to $15-30 \%$ of the April-October rainfall. In an extreme year (e.g., 1980), up to $75 \%$ of the seasonal rainfall could be attributed to cloudbands and their interactions with meteorological features.

\section{Conclusions}

This study examined NWCB activity over Australia from 1975 to 1999 and an index representing cloudband activity over

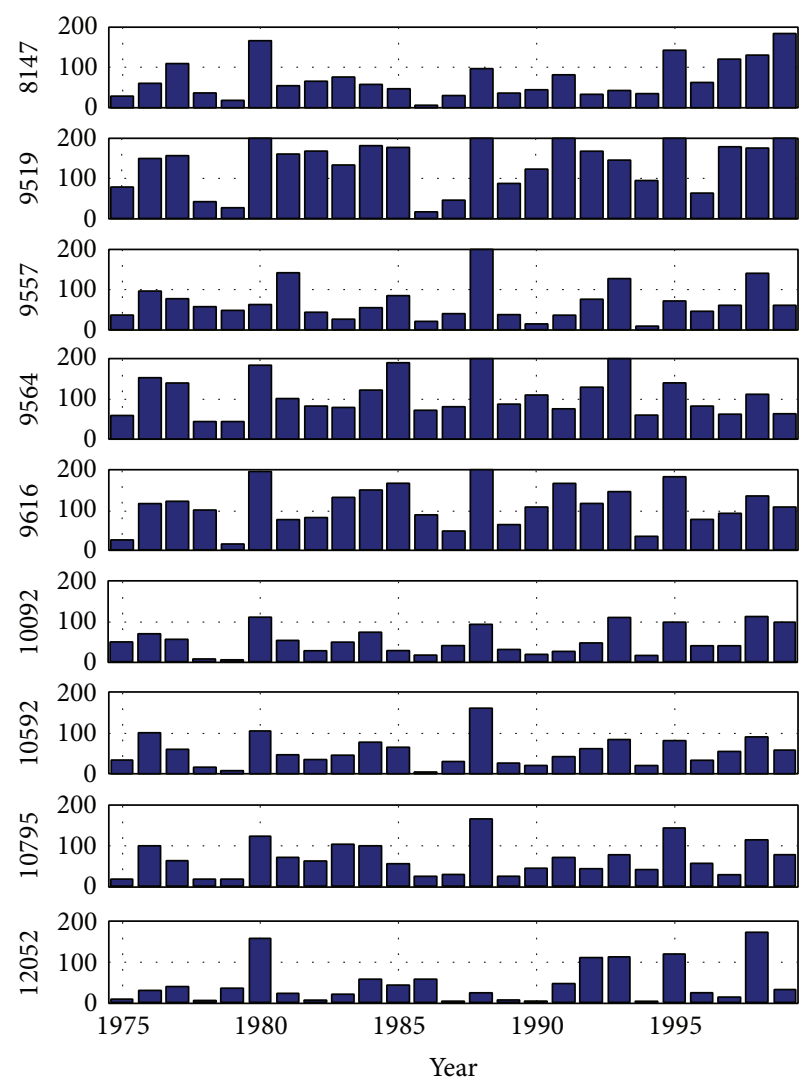

FIGURE 11: The seasonal (April-October) NWCB-related rainfall for 1975-1999 recorded at the nine SW rainfall stations.

Australia between 1974 and 1999 was created and dissected to create regional indices, which showed the NWCB activity had a NW-SE bias. Atmospheric and oceanic influences on cloudband activity were examined and revealed that NWCB activity was related to the MJO, Indian Ocean dipole, El Niño southern oscillation, and SSTs in the NWCB formation region. These influences were not independent; thus NWCB activity over Australia was hard to predict.

The NWCB-related rainfall data were collated from the regional indices to show the cloudband-related rainfall for each $2.5^{\circ}$ grid point across Australia. Most cloudband-related rainfall occurred in coastal regions, where the interaction of NWCBs with other features, such as frontal disturbances, increased the rainfall. Cloudband-related rainfall was also found to be spatially and temporally variable.

\section{Conflict of Interests}

The authors declare that there is no conflict of interests regarding the publication of this paper.

\section{Acknowledgments}

The Gascoyne-Murchison Strategy and the Climate Variability in Agriculture Program funded this research. The authors would like to thank the Climate Diagnostics Centre, Boulder, 


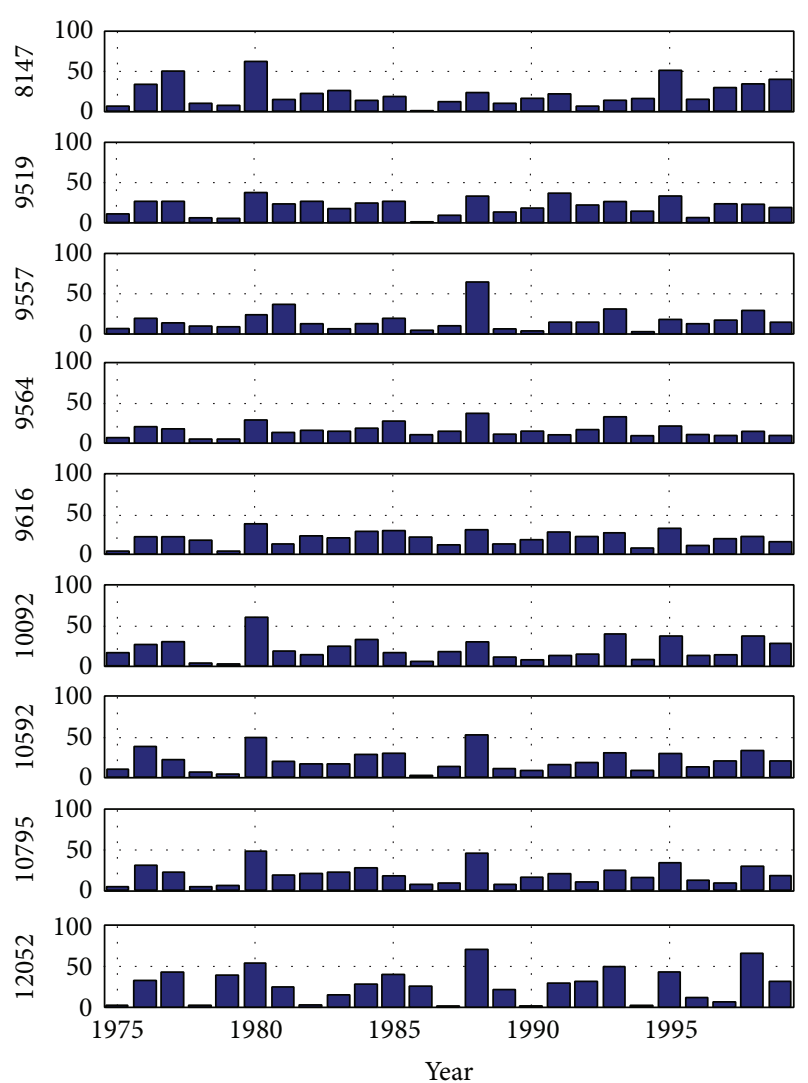

FIGURE 12: Percentages of NWCB-related rainfall contributions to the total April-October rainfall for 1975-1999 for the nine SW rainfall stations.

for kindly providing the Reynolds reconstructed SST and reanalysis data, and the Australian Bureau of Meteorology for their rainfall data sets and processed GMS-5 satellite images (courtesy of the Japan Meteorological Agency). They would also like to thank the following people for their advice and guidance with this research: Dr. Neville Nicholls and Dr. Wasyl Drosdowsky, Australian Bureau of Meteorology Research Centre; Dr. William Wright, NCC; John Cramb and Joseph Courtney, Australian Bureau of Meteorology; Dr Gary Meyers, CSIRO Marine Research; Dr. Ian Smith, CSIRO Division of Atmospheric Research; Professor Greg Ivey, UWA; and Alisa Krasnostein, UWA.

\section{References}

[1] W. J. Wright, “Tropical-extratropical cloudbands and Australian rainfall: I. Climatology," International Journal of Climatology, vol. 17, no. 8, pp. 807-829, 1997.

[2] W. K. Downey, T. Tsuchiya, and A. J. Schreiner, "Some aspects of a northwestern Australian cloudband," Australian Meteorological Magazine, vol. 29, no. 3, pp. 99-113, 1981.

[3] N. C. G. Hart, C. J. C. Reason, and N. Fauchereau, "Cloud bands over southern Africa: seasonality, contribution to rainfall variability and modulation by the MJO," Climate Dynamics, vol. 41, no. 5-6, pp. 1199-1212, 2013.
[4] I. Kuhnel, "Tropical-extratropical cloudband climatology based on satellite data," International Journal of Climatology, vol. 9, no. 5, pp. 441-463, 1989.

[5] R. G. Tapp and S. L. Barrell, "The north-west Australian cloud band: climatology, characteristics and factors associated with development," Journal of Climatology, vol. 4, no. 4, pp. 411-424, 1984.

[6] B. Geerts and E. Linacre, "Northwest cloud bands," University of Wyoming, 1998, http://www-das.uwyo.edu/ geerts/cwx/notes/chap08/nw_cloud.html.

[7] J. S. Frederiksen and C. S. Frederiksen, "Twentieth century winter changes in Southern Hemisphere synoptic weather modes," Advances in Meteorology, vol. 2011, Article ID 353829, 16 pages, 2011.

[8] C. C. Ummenhofer, M. H. England, P. C. Mclntosh et al., "What causes southeast Australia's worst droughts?" Geophysical Research Letters, vol. 36, no. 4, Article ID L04706, 2009.

[9] A. Hoell, M. Barlow, and R. Saini, "Intraseasonal and seasonalto-interannual indian ocean convection and hemispheric teleconnections," Journal of Climate, vol. 26, no. 22, pp. 8850-8867, 2013.

[10] G. A. Meehl, "The annual cycle and interannual variability in the tropical Pacific and Indian Ocean regions," Monthly Weather Review, vol. 115, no. 1, pp. 27-50, 1987.

[11] P. J. Webster, V. O. Magaña, T. N. Palmer et al., "Monsoons: processes, predictability, and the prospects for prediction," Journal of Geophysical Research C: Oceans, vol. 103, no. 7, pp. 14451-14510, 1998.

[12] R. A. Madden and P. R. Julian, "Observations of the 40-50-day tropical oscillation-a review," Monthly Weather Review, vol. 122, no. 5, pp. 814-837, 1994.

[13] A. C. Subramanian, M. Jochum, A. J. Miller, R. Murtugudde, R. B. Neale, and D. E. Waliser, "The Madden-Julian oscillation in CCSM4," Journal of Climate, vol. 24, no. 24, pp. 6261-6282, 2011.

[14] P. J. Webster, "The Asian-Australian monsoon system: a prospectus for a research program. Draft recommendations from the St Michaels, Maryland, monsoon workshop July 2830, 1998," U.S. Climate Variability and Predictability Research Program (CLIVAR) Working Group Report, 1998.

[15] N. H. Saji, B. N. Goswami, P. N. Vinayachandran, and T. Yamagata, "A dipole mode in the tropical Indian ocean," Nature, vol. 401, no. 6751, pp. 360-363, 1999.

[16] S. Sankar, M. R. R. Kumar, and C. Reason, "On the relative roles of El Nino and Indian Ocean Dipole events on the monsoon onset over Kerala," Theoretical and Applied Climatology, vol.103, no. 3-4, pp. 359-374, 2011.

[17] I. D. Bell, Extratropical cloud systems: satellite interpretation and three-dimensional airflows [Ph.D. thesis], Monash University, Melbourne, Australia, 1982.

[18] I. Kuhnel, "Tropical-extratropical cloudbands in the Australian region," International Journal of Climatology, vol. 10, no. 4, pp. 341-364, 1990.

[19] W. J. Wright, Synoptic and climatological factors influencing winter rainfall variability in Victoria [Ph.D. thesis], The University of Melbourne, Melbourne, Australia, 1987.

[20] J. S. Godfrey, "The effect of the Indonesian throughflow on ocean circulation and heat exchange with the atmosphere: a review," Journal of Geophysical Research C: Oceans, vol. 101, no. 5, pp. 12217-12237, 1996.

[21] A. C. Hirst and J. S. Godfrey, "The response to a sudden change in Indonesian throughflow in a global ocean GCM," Journal of Physical Oceanography, vol. 24, no. 9, pp. 1895-1910, 1994. 
[22] G. Meyers, "Variation of Indonesian throughflow and the El Niño-Southern Oscillation," Journal of Geophysical Research C: Oceans, vol. 101, no. 5, pp. 12255-12263, 1996.

[23] G. A. Meehl, "A coupled air-sea biennial mechanism in the tropical Indian and Pacific regions: role of the ocean," Journal of Climate, vol. 6, no. 1, pp. 31-41, 1993.

[24] G. A. Meehl, "Coupled land-ocean-atmosphere processes and South Asian monsoon variability," Science, vol. 266, no. 5183, pp. 263-267, 1994.

[25] N. Nicholls, L. Chambers, M. Haylock, C. Frederiksen, D. Jones, and W. Drosdowsky, Climate Variability and Predictability for South-West Western Australia: Phase 1 Report to the Indian Ocean Climate Initiative, Bureau of Meteorology Research Centre, Melbourne, Australia, 1999.

[26] J. Gentilli, Australian Climate Patterns, Thomas Nelson, Melbourne, Australia, 1972.

[27] B. Lavery, G. Joung, and N. Nicholls, "An extended high-quality historical rainfall dataset for Australia," Australian Meteorological Magazine, vol. 46, no. 1, pp. 27-38, 1997. 

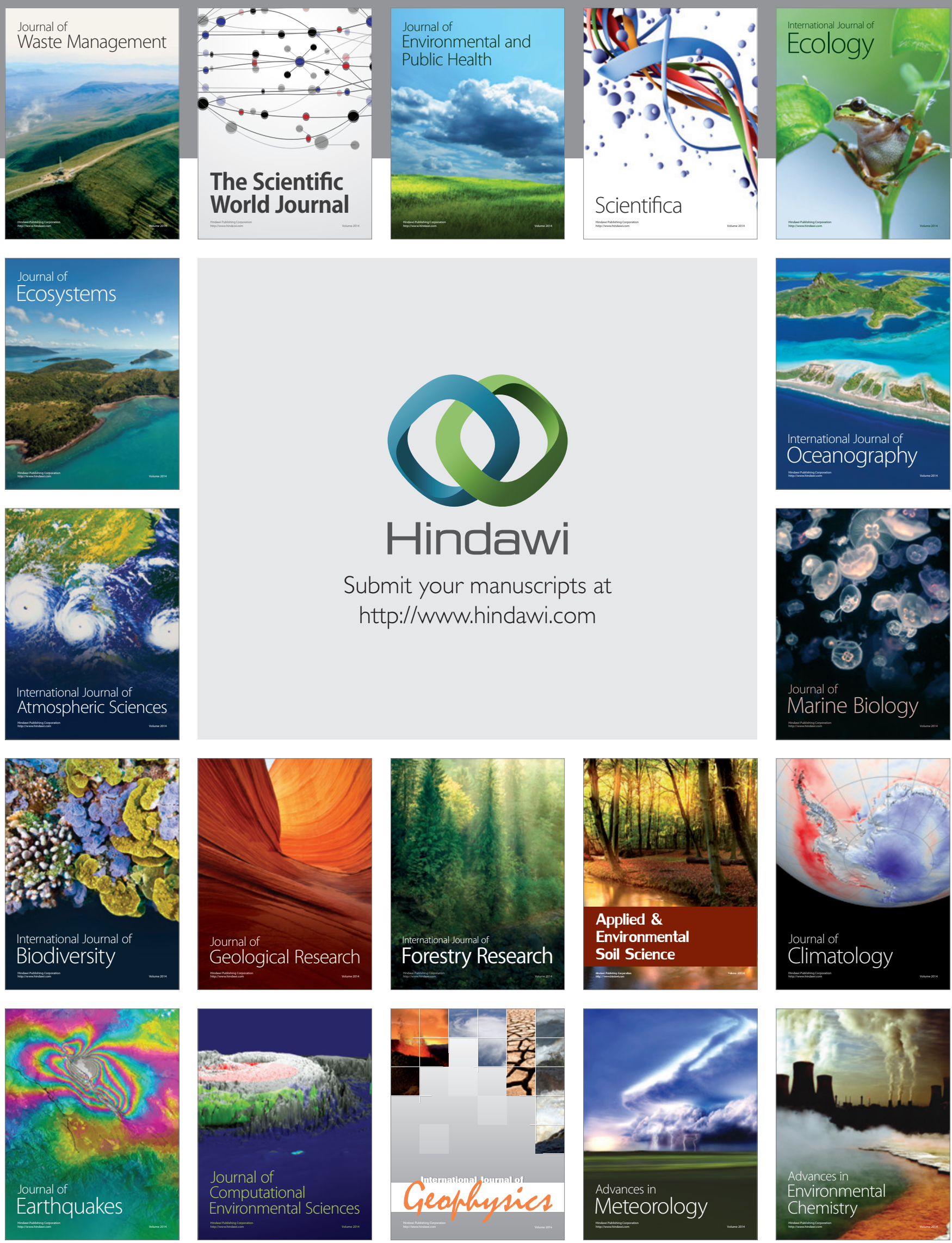